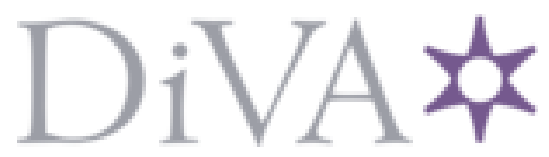

http://www.diva-portal.org

\title{
Postprint
}

This is the accepted version of a paper published in International Journal of Rail Transportation. This paper has been peer-reviewed but does not include the final publisher proof-corrections or journal pagination.

Citation for the original published paper (version of record):

Fröidh, O., Sipilä, H., Warg, J. (2014)

Capacity for express trains on mixed traffic lines.

International Journal of Rail Transportation, 2(1): 17-27

http://dx.doi.org/10.1080/23248378.2013.878292

Access to the published version may require subscription.

N.B. When citing this work, cite the original published paper.

Permanent link to this version:

http://urn.kb.se/resolve?urn=urn:nbn:se:kth:diva-165404 


\section{Capacity for express trains on mixed traffic lines}

Oskar Fröidh ${ }^{\mathrm{a}}$, Hans Sipiläb ${ }^{\mathrm{b}}$ Jennifer Warg

${ }^{a b c}$ Div. of Traffic and Logistics, KTH Royal Institute of Technology, SE-100 44

Stockholm, Sweden

Fax +468212899

a Corresponding author: oskar.froidh@abe.kth.se. Telephone +46 87908379

b hans.sipila@abe.kth.se. Telephone: +46 87908637

c jennifer.warg@abe.kth.se Telephone: +46 87908345

version 2013-12-03 with revised illustrations (for B/W) figure 1, 2, 3, 4 and 6 


\section{Capacity for express trains on mixed traffic lines}

Mixed traffic with large speed differences between fast and slower trains consumes more capacity and makes the system sensitive to disruptions. This paper focuses on adequate train configuration for increasing the top speed for express trains like the Green Train and how that affects capacity on lines with heterogeneous traffic. Microscopic simulation of a future timetable selected by criteria revealed by analytical timetable analysis for a chosen structure of services combines the advantages of two methods and makes it possible to reveal relevant characteristics for different alternatives. Punctual short stops through better train layout and skip-stop operation for regional trains are a few of the measures that are shown to have compensating effects for the increase in capacity utilisation and can reduce disruptions. Although it is possible to reduce the perturbations by means of different measures, the basic problem with mixing fast and slower trains on the same line still remains.

Keywords: Green Train; freight train; mixed traffic; conventional lines; train performance; punctuality

\section{Introduction}

\subsection{Traffic with the Green Train}

The Green Train concept is primarily intended for conventional lines with mixed traffic in Scandinavia. The Scandinavian railway network is characterized by a large proportion of single-track lines and different kinds of freight and passenger services often have to share tracks. Some new sections with high-speed standard are making the network heterogeneous. Express trains (here, ‘express train’ denotes a high-speed train on conventional lines) like the tilting X 2000 in Sweden today reach average speeds of up to $165 \mathrm{~km} / \mathrm{h}$ where capacity is available and the line standard permits speeds of up to 200 km/h. Technologies developed in the Green Train programme, for example improved running gear and active suspension (ALS/AVS) allow the maximum speed to be raised to $250 \mathrm{~km} / \mathrm{h}$ provided the existing infrastructure can be upgraded for higher 
speeds [2, 5]. This offers the opportunity to shorten travelling times by approx. $10 \%$ compared to the X 2000 and attain significant market effects [4, 5].

However, increasing the gap in running times between the fastest and the slowest trains consumes capacity - the timetabling flexibility might decrease and the need to overtake slower trains increases. The heterogeneity can be exemplified by the average speeds of different services: freight trains today in general reach average speeds of $60-85 \mathrm{~km} / \mathrm{h}$, while regional services, depending on the number of stops, reach $60-100$ $\mathrm{km} / \mathrm{h}$ - and mixing these service supplies with express trains at $160-180 \mathrm{~km} / \mathrm{h}$ average speed is a challenge as regards capacity.

One part of the Green Train research and development programme aimed to determine train performance parameters for general use on the Scandinavian networks. The capacity situation on lines with mixed traffic has been analysed to overcome the capacity constraints. It is also desirable to decrease perturbations and improve punctuality, which has been a widespread problem on express train services on many Swedish mixed traffic lines.

\subsection{Aim}

The aim of this paper is to analyse and highlight how increased speeds for express train services affect service supply and capacity on lines where freight, regional and fast passenger trains share tracks and to evaluate potential measures to release capacity. One objective is to keep capacity utilisation at the same level as without the speed increase, which means maintaining the number of possible (attractive to the market) train paths while keeping a similar level of reliability. Focus lies on double-track lines. 


\section{Capacity characteristics}

\subsection{Definition of track capacity}

Track capacity is not an unambiguous concept. A common way to describe the maximum capacity is by counting the number of train paths that can be operated per hour. This can for example be done with help of the compression method described in UIC Code 406 [13], where capacity consumption is defined as the portion of the total available time that is occupied by scheduled trains including time supplements. For further evaluation it is recommended to analyse the possibility to schedule additional train paths for different kinds of services. It is also stated that the number of trains, average speed, heterogeneity and stability have to be in balance to reach a wellfunctioning system $[1,6]$.

As capacity is a complex definition, one measure is often not sufficient to describe it. An important aspect for defining if a timetable is operational is reliability. Vromans, Dekker and Kroon [14] describe an analytical method to evaluate how the minimum gap between two trains affects reliability. An adequate method of evaluating how a system reacts to delays and how changes affect this is simulation, as described for example in $[3,10]$. But capacity might also include a wider perspective, for example market aspects: do the services on a specific line sequence during a specific time period satisfy the desired frequencies and departure or arrival times for all services on the line?

\subsection{Common capacity conflicts with increased average speed heterogeneity}

Raising the speed of the express trains means increasing the difference in average speed compared to other (slower) trains. This consumes capacity. Conflicts between desires to operate different train services on certain train paths arise for express trains in particular on those lines where commuter traffic is to be operated with high frequency (twice an 
hour or more often) and to a regular interval timetable. Due to different average speeds, the available timetable space between two commuter train paths might not be sufficient to schedule an express train with full speed. This conflict can be resolved by time supplements for the faster train, passing or deviation from the desired interval timetable. However, headways might become small, which for example may mean that even relatively small delays can make the express train miss its timetable slot and end up behind the regional train. This causes the express train's delay to grow rapidly. As express trains operate over long distances, delays may accumulate of more missed slots during the journey and eventually be considerable.

Conflicts between the express train and other passenger trains operating at higher average speeds due to fewer stops can in general be resolved smoothly. However, conflicts also occur between express trains and freight trains, mainly where the major rail freight flows coincide with the interregional passenger flows. Since the freight trains as a rule have lower priority, they have to move out of the way onto overtaking sidings when they are caught up by an express train (see the example in Figure 1). This means longer running times for the freight trains but is otherwise a relatively simple solution provided that there are overtaking tracks at regular distances along the lines. However, it reduces their average speed and increases capacity utilisation. 

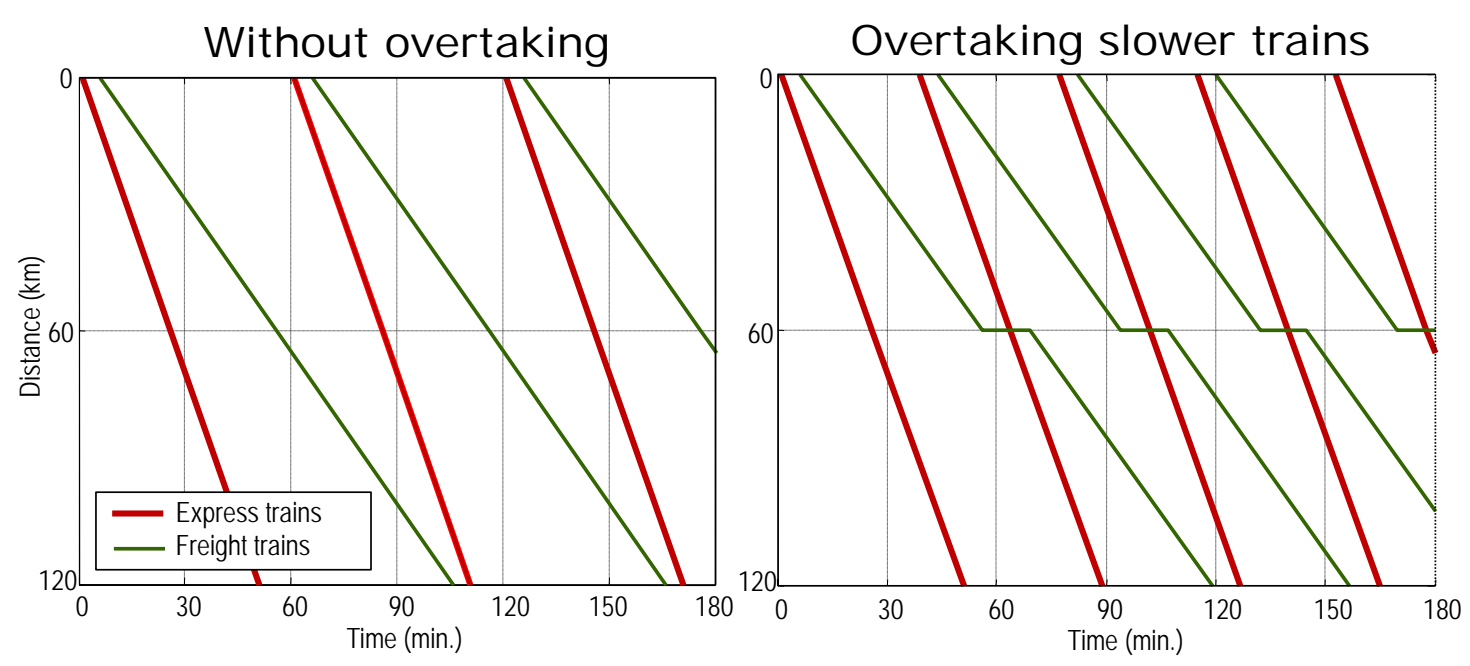

Figure 1. Examples of outline timetables with and without overtaking tracks on a line with mixed express train and freight train traffic. Overtaking allows more trains to be operated.

In addition to capacity constraints, timetable planning means that departure and arrival times might be changed in a way which does not suit the travellers or freight customers. These changes can also spread to connecting lines by trains originating or terminating on these. Similar effects apply in the case of delays: if the speed increase causes secondary delays for other trains operating on line sections, these will spread to other lines or sections in case the possibilities for recovery are too small.

In [15] it was shown that in particular the degree of heterogeneity of the services is important. On the line section with larger differences between the average speeds of the slowest and fastest trains, more secondary delays appear compared to sections operated by more homogeneous traffic.

Also Lindfeldt [8] pointed out that train frequency and speed are more important impact factors for delay development compared to the variation in delays and distances between overtaking stations. Using multiple simulation of three different services, Lindfeldt [7] confirms that density is important. The more services per time, the more 
both scheduled and secondary delays increase. He also considers that this effect is smaller when the timetable becomes more homogenous.

On single-track lines with equally fast trains it is an advantage to raise the speeds since it reduces the number of train crossings along the line, see Figure 2. But where faster trains catch up slower trains, for example freight trains, the same capacity limitation and need for places to overtake arise as on double-track lines as was shown in Figure 1.

Not so fast trains

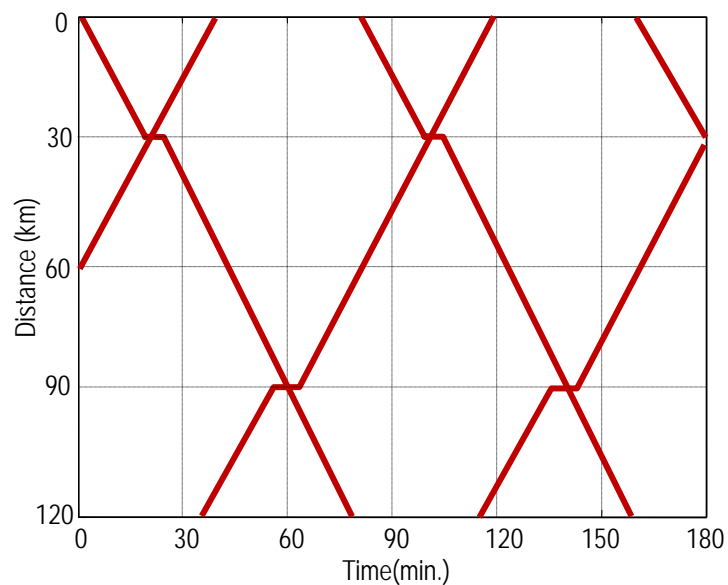

Faster trains

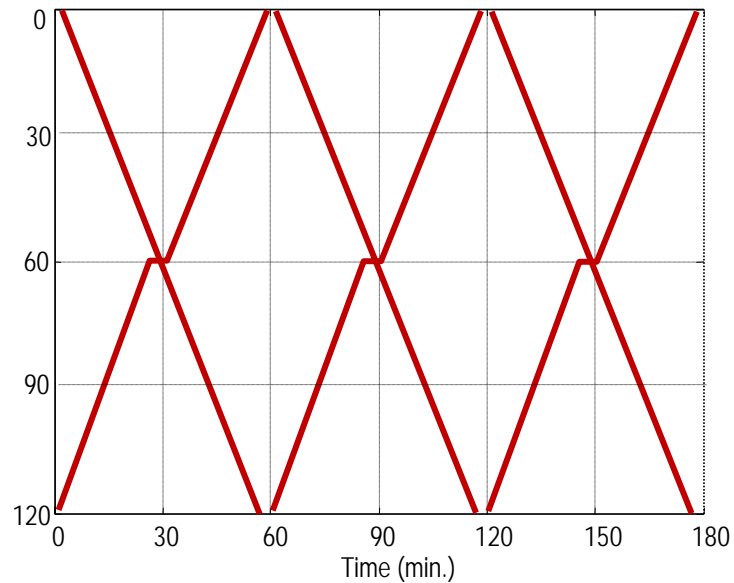

Figure 2. A line with single track and train crossings with regular frequency of services. Higher speeds mean that the timetable becomes more robust through fewer train crossings and in some cases also opportunities for higher frequency.

\subsection{Principal method to analyse capacity}

An analysis of capacity for express trains in mixed services was made in a three-step process. First, different train performance on a number of lines were analysed to generalise a train concept. In step 2, the effects of a speed increase on timetable characteristics for a double-track line with dense, heterogeneous traffic were determined and possible measures tested. The evaluation was completed by further capacity analysis with simulation in step 3. Combining analysis of train configuration with 
timetable analysis and simulation, this method allows analysing capacity using adequate train types for future express trains. The multiple simulation tool RailSys [10] is used in step 1 and 3 and completed with the analytical timetable analysis application TVEM (Timetable Variant Evaluation Model) [9]. This makes is possible to reduce some of the limitations of these methods and gain more evaluation criteria. Further details can be found in the following sections.

\section{Train performance}

\subsection{Dynamic characteristics}

Taking advantage of increased track speeds is linked to train performance factors, mainly top speed. Higher speeds increase the total running resistance and to reach them, trains need relatively high installed traction power. But high-speed trains typically have moderate acceleration capabilities at lower speeds compared to trains designed for frequent stops and lower top speeds. Aerodynamically induced forces are typically proportional to the speed squared and thus become important for high-speed or express trains and the need for sufficient power. Other aspects that add to the total running resistance are rolling, curve and gradient resistance.

\subsection{Running time calculations}

A study was carried out focusing on running time for the Green Train on different relations in Sweden [11]. RailSys is used both for pure running time calculations and simulations discussed in section 4. Trains with different top speed, power to mass ratio and starting acceleration were modelled. Train configurations for running time calculations are set up by varying installed traction power, start acceleration and top speed. Train length 155 m (6 cars), weight 360 ton and mass supplement for rotating 
masses $5.6 \%$ are kept constant. Train resistance is modelled as $D=A+B v+C v^{2}$ with corresponding coefficient values $2400 \mathrm{~N}, 60 \mathrm{~kg} / \mathrm{s}$ and $6.5 \mathrm{~kg} / \mathrm{m}$. Curvature and tunnel resistance is not considered in this study. A constant braking of $0.6 \mathrm{~m} / \mathrm{s}^{2}$ is applied. Figure 3 shows traction force and acceleration diagrams for three combinations of power to weight ratio and start acceleration.
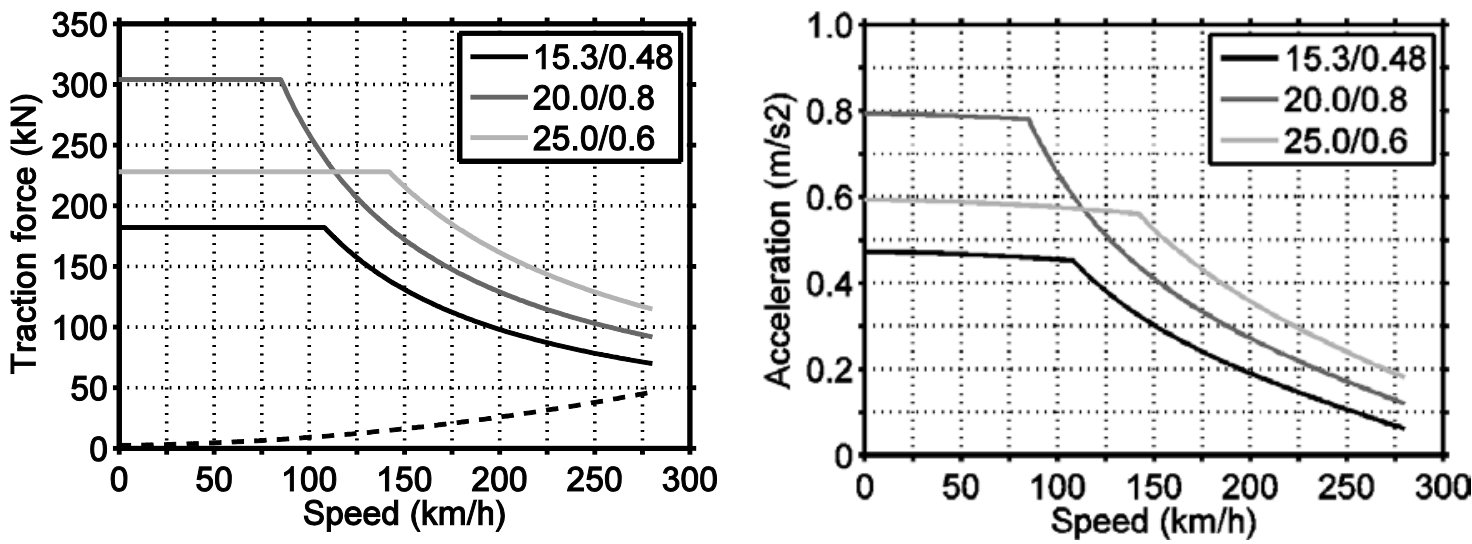

Figure 3. Example of traction force and acceleration diagrams on level track (0\%o gradient). Dashed line is train resistance.

Calculations of maximal train speed in horizontal curves using curve radii data from existing lines and combinations of cant (D) and cant deficiency (I) give modified static speed profiles. Cant in curves is the amount by which the outer rail is raised above the inner one. Cant deficiency is proportional to remaining track plane acceleration, and is a measure of the additional cant needed to exactly balance the quasi-static lateral acceleration. Using trains with carbody tilting and bogies with good running characteristics can partly compensate for sharp curves. There is a need to limit the maximum allowed cant deficiency for higher speeds with regard to crosswinds. Slow and heavy trains also impose a limitation on maximum allowed cant value in order to avoid too high a cant excess (negative cant deficiency). 
Figure 4 shows examples of existing and new speed profiles on the Western Main Line. The cant (D) is $150 \mathrm{~mm}$ for the existing profiles with equilibrium cant 300 and $325 \mathrm{~mm}(\mathrm{D}+\mathrm{I})$, and $160 \mathrm{~mm}$ for the new profiles. An example of the cumulative distribution of speeds over distance and the effect of allowing a higher cant deficiency between Stockholm and Gothenburg is also shown in Figure 4 for the new profiles. The difference between equilibrium cant 325 and $435 \mathrm{~mm}$ is that the latter targets trains with carbody tilting, enabling higher speeds with retained comfort.

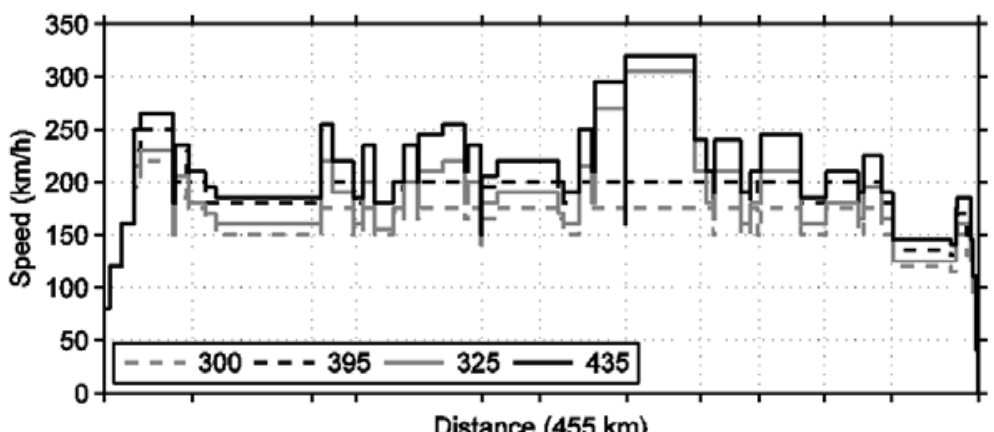

Distance (455 km)

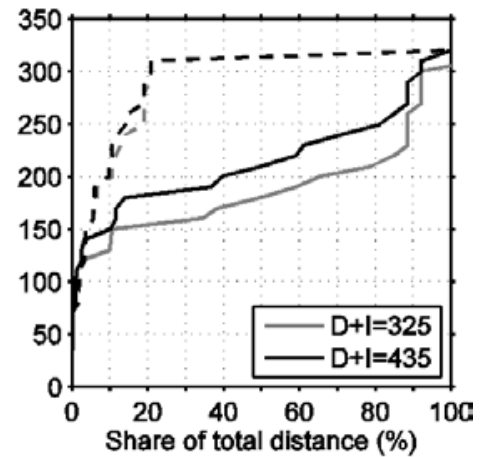

Figure 4. Speed profiles for different equilibrium cant values (mm) and cumulative distribution of possible line speeds over total distance for two equilibrium cant values on the Western Main Line Stockholm - Gothenburg (solid lines). For comparison dashed lines on cumulative plot shows the same relation via the studied Götaland highspeed line, dimensioned for $320 \mathrm{~km} / \mathrm{h}$ top speed. Transition curves have not been considered.

The impact on running times applying combinations of different power to mass ratios, starting accelerations, top speeds and static speed profiles based on different equilibrium cant values are exemplified in Figure 5. Solid lines show a non-stop pattern, dashed lines a service with eight intermediate stops on the existing line StockholmGothenburg (455 km). Considering pure running times, including acceleration and deceleration but without stop times, indicate that the benefits of increasing power and starting acceleration have a relatively minor effect in the non-stop case. In the case with 
intermediate stops, however, the differences are clearer. Comparing the "weakest" and “strongest” train configuration gives a difference of more than two minutes per $100 \mathrm{~km}$, which translates to ten minutes in total over the full distance. Similarly, the difference on the relation Stockholm-Malmö-Copenhagen $(657 \mathrm{~km})$ for equilibrium cant $435 \mathrm{~mm}$ and train top speed $280 \mathrm{~km} / \mathrm{h}$ with 13 intermediate stops is just over two minutes per $100 \mathrm{~km}$ and 14 minutes in total. Speed profiles with high variation can also have a clear impact on the running times between trains with different power to mass ratio, even though the number of scheduled stops might be low.

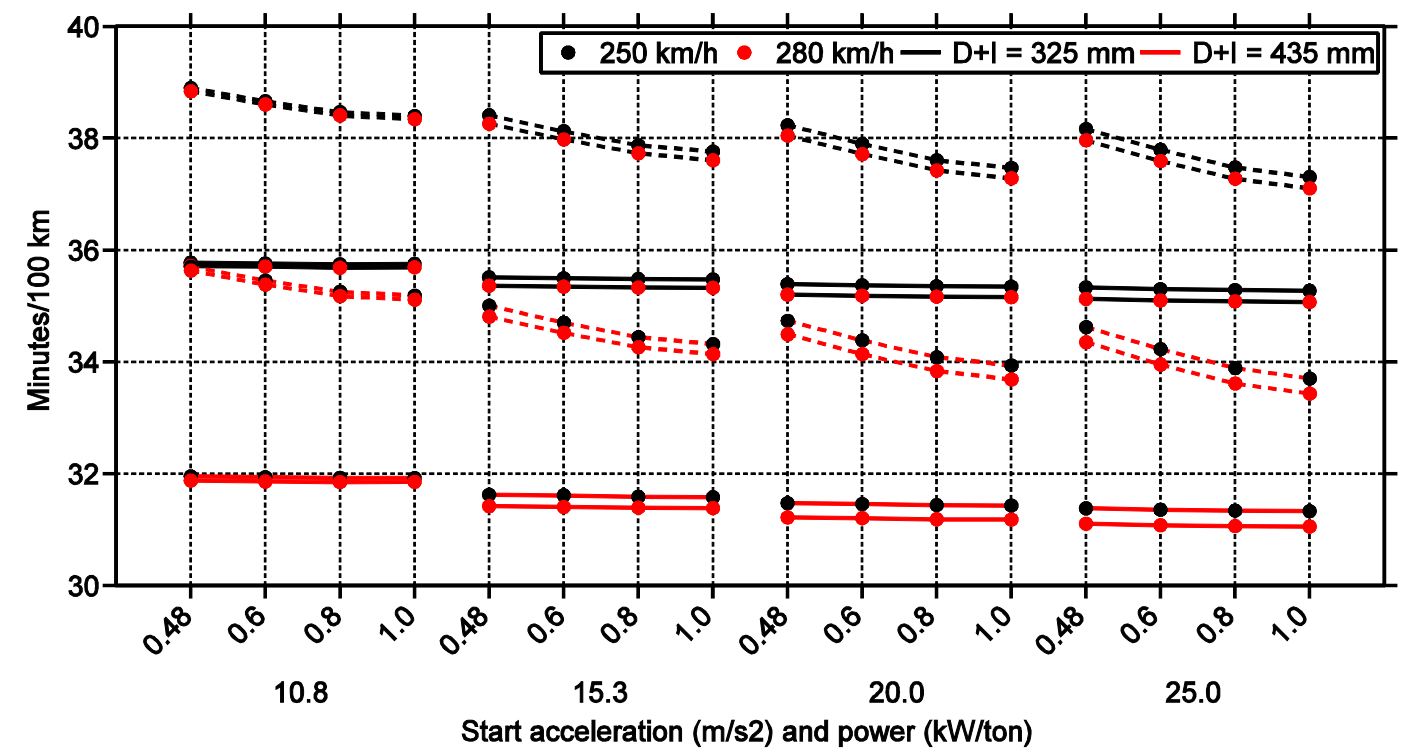

Figure 5. Running times in minutes per $100 \mathrm{~km}$ for combinations of power to mass ratio, starting acceleration, top speed and equilibrium cant. Stockholm-Gothenburg with non-stop trains (solid lines) and with eight intermediate stops (dashed lines). Dwell times at stations are not included.

\subsection{Train characteristics and influence on capacity}

After analysing a great many combinations, it is quite clear that a generally usable train should have performance that offers short running times on tracks of different design. A future express train in long-distance traffic on winding lines should have tilting, a 
maximum permitted speed of at least $250 \mathrm{~km} / \mathrm{h}$, or more if the track is new and therefore has better geometry, a starting acceleration between 0.6 and $0.8 \mathrm{~m} / \mathrm{s}^{2}$ and an output in relation to its mass of between 15 and $20 \mathrm{~kW} /$ ton (the higher the top speed, the higher the value).

A train for traffic on alternating conventional and high-speed lines should have a top speed of between 280 and $320 \mathrm{~km} / \mathrm{h}$ and slightly higher output per mass of between 20 and $25 \mathrm{~kW} /$ ton for shorter running times. The higher the proportion of high-speed line the less the benefit from tilting and the greater the benefit from higher top speed [7].

In real operations with train interactions and delay propagations train performance becomes even more important since it influences the ability to reduce delays, i.e. make the train more resistant to perturbations. Express trains in particular are sensitive to delays due to time consuming decelerations and accelerations when obstructed by other trains. This is of course linked to the operating timetable and the amount of allowance included. Other trains also benefit from this since the trains in question can clear certain key sections, e.g. at stations, faster.

\section{Capacity analysis of express trains on lines with mixed services}

\subsection{Southern Main Line case study}

In order to determine how increased speeds for express trains affect capacity and how to compensate for these effects, a capacity evaluation with a focus on the Swedish Southern Main Line which links Stockholm with Malmö and Copenhagen, the $400 \mathrm{~km}$ section between Katrineholm and Hässleholm, was carried out [12]. Express trains have an important function on this section and shorter travel times are estimated to increase travelling by train [5]. But combined with several important markets for other passenger 
trains, for example regional trains using parts of the section, as well as freight trains, the double-track line is congested and punctuality low [12].

The analysis was limited to the passenger traffic's peak hour in the southbound direction but was also considered to be applicable to the northbound direction taking into account the fact that differences in the infrastructure (e.g. stations with overtaking tracks on only one side), delay distributions and the distribution over the day (traffic peaks for different services possibly coincide to a greater or lesser degree). Number, kind and frequency of services were estimated for year 2030 based on today's supply and development plans. A train type with a top speed of $250 \mathrm{~km} / \mathrm{h}$ and adequate characteristics was chosen based on the findings from the performance analysis.

\subsection{Method}

In order to cover several different aspects and decrease timetable dependencies, an analytical timetable analysis was combined with simulation. In the first step, the analytical timetable analysing application TVEM [9] was used. In TVEM, the available capacity is modelled by infrastructure patterns including capacity aspects such as headways etc. The desired supply of service is described by properties for different services (running times, frequency, etc.) as well as the starting sequence between them. The output is all timetables that satisfy the criteria.

Input data was chosen based on today’s service supply and future plans and limited to a number appropriate for this study. One important criterion was to keep the departures as spread as possible, preferably with fixed intervals in regional services, with as low a scheduled delay as possible for all services. In addition to this, TVEM can give an indication of the possibilities to add train paths. The number of generated timetables that satisfy the desired criteria indicate a system’s timetable flexibility and 
this was used to compare different scenarios [12]. Based on how the generated timetables fulfil market requirements, added scheduled delay for services and the possibility to add train paths, the best timetable was chosen for the next step, simulation.

The chosen timetable was modelled in the software tool RailSys [10] and reworked to be more detailed. On that timetable, delays according to today's level were applied and simulation of the selected timetable performed to show the system's handling of delays [12].

Analyses were made with today’s X 2000 at $200 \mathrm{~km} / \mathrm{h}$ top speed as well as a future Green Train with a top speed of $250 \mathrm{~km} / \mathrm{h}$ (see section 3). Based on the results, different measures to compensate the effect of increased speed for the express trains were evaluated in the same way and compared to the basic alternatives.

\subsection{Timetable analysis and simulation results}

The analysis showed that increasing the speed of the express trains affects both timetabling flexibility and reliability in terms of delays.

Today, a running time supplement is needed to schedule an express train between two regional trains in a fixed interval timetable with departures every 20

minutes. A spread of three regional trains per hour is also shown to be questionable. To avoid too much scheduled delay but take market wishes into account, the analysis was made with a 15-20-25 minute headway between the regional trains.

The possibility to reduce the number of stops was analysed for one of the two hourly express train departures in order to reduce the travelling time between endpoints. The available capacity did not, however, allow for a non-stop journey without further measures, but the intermediate stops were reduced to two. With this adjustment of the average speed, the total travel time could be reduced by around $16 \%$ compared to an 
X 2000 with today’s stopping pattern. For the second hourly high-speed train, however, an additional scheduled delay was needed so that the gain in travel time compared to the X 2000 was 15 min (9\%).

The analysis showed that timetable flexibility is very low for this service supply. With X 2000, the number of possible timetables is considerably higher, which makes it easier to adapt to market wishes. Some measures are required, for example overtakings, additional time supplement and sometimes changes to the fixed interval timetables. In addition, headways are sometimes quite short. Capacity utilisation is in particular high on sections with a high average speed for the Green Train. The simulation of the timetable showed that this causes a considerable increase in the express train's delay, which already occurs in the scenario without speed increase.

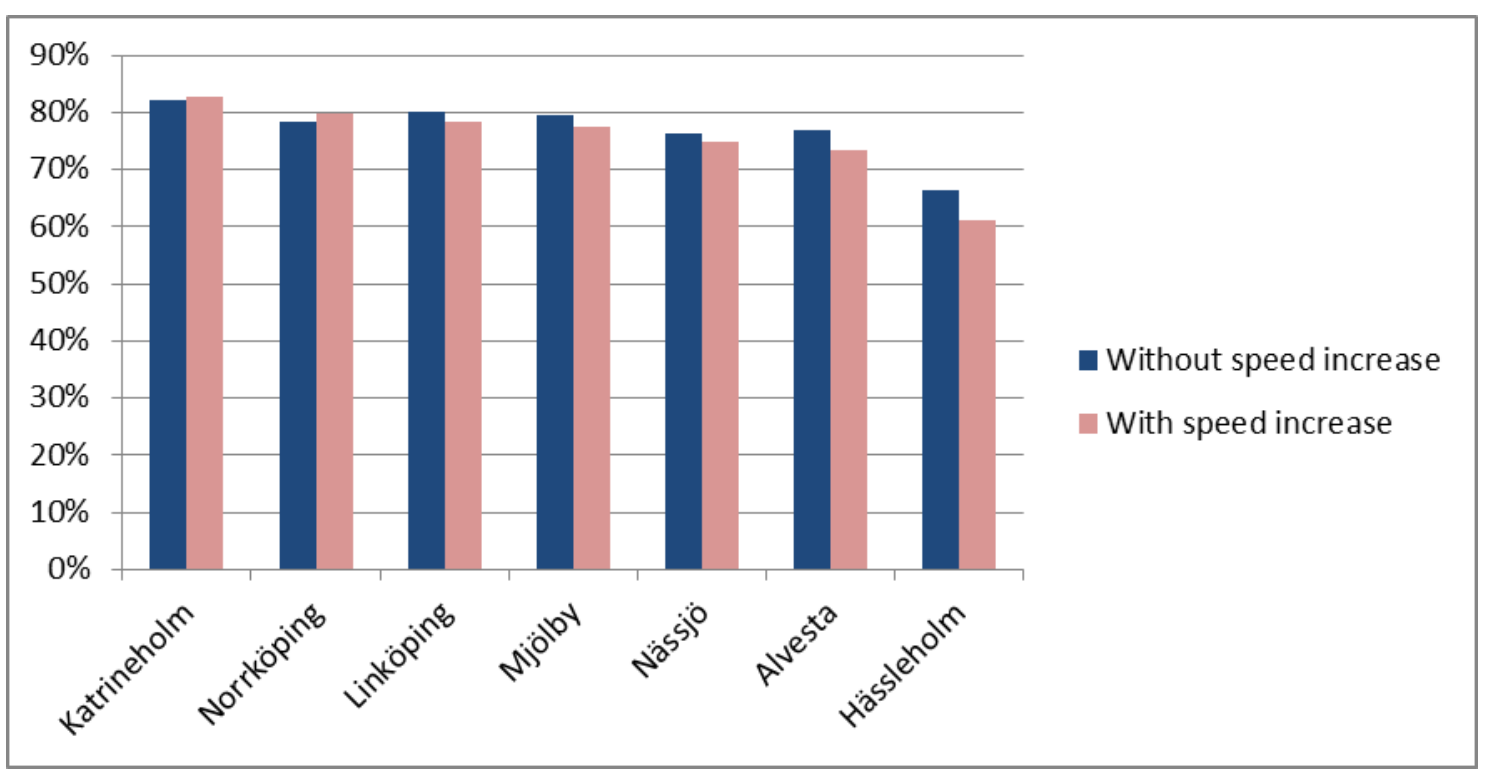

Figure 6. Simulated punctuality ( $\leq 5$ min's) for southbound express trains on the studied section.

The analysis showed that increased speed for express trains consumes capacity, which appears in the way that delays increase, the number of possible train paths is reduced (decreased timetable flexibility) and running times are prolonged for Intercity, 
regional or freight services. On line sections with a lower top speed than $250 \mathrm{~km} / \mathrm{h}$, the difference in average speed between express trains and other trains is on a more even level and effects on capacity are smaller.

In the development of the Green Train, special attention has been paid to measures to reduce the total level of perturbation. The combined timetable and simulation method was used to analyse how these measures can compensate for the negative effects.

As described earlier, the Southern Main Line is heavily loaded and the level of perturbation is already high. This is also the case on other lines where the new train could have significant positive market effects. However, in the basic scenario, delay levels comparable to X 2000 on the same line have been used. The scenario with "reduced dwell time delays for express trains" is based on research results [5] that make it possible to reduce delays through better entrances and interior layouts, including luggage handling. The analysis shows that this can partly compensate for the negative effect of the speed increase on capacity. Additional time supplements for express trains would also be an effective way to both increase timetable flexibility and strengthen reliability but is counterproductive as regards shorter travelling times.

Another way to reduce the gap in average speeds is to increase other trains’ speed, for example by introducing skip-stop for regional trains with many stops or by increasing the top speed of freight trains (see Figure 7). Regional skip-stop was shown to also allow fleeting for the express trains. All in all, a 10\% gain in punctuality could be achieved. However, to best utilise express train fleeting they should cover different geographical markets. Gains in timetable flexibility could be shown for both faster freight trains and skip-stop for the regional trains. 


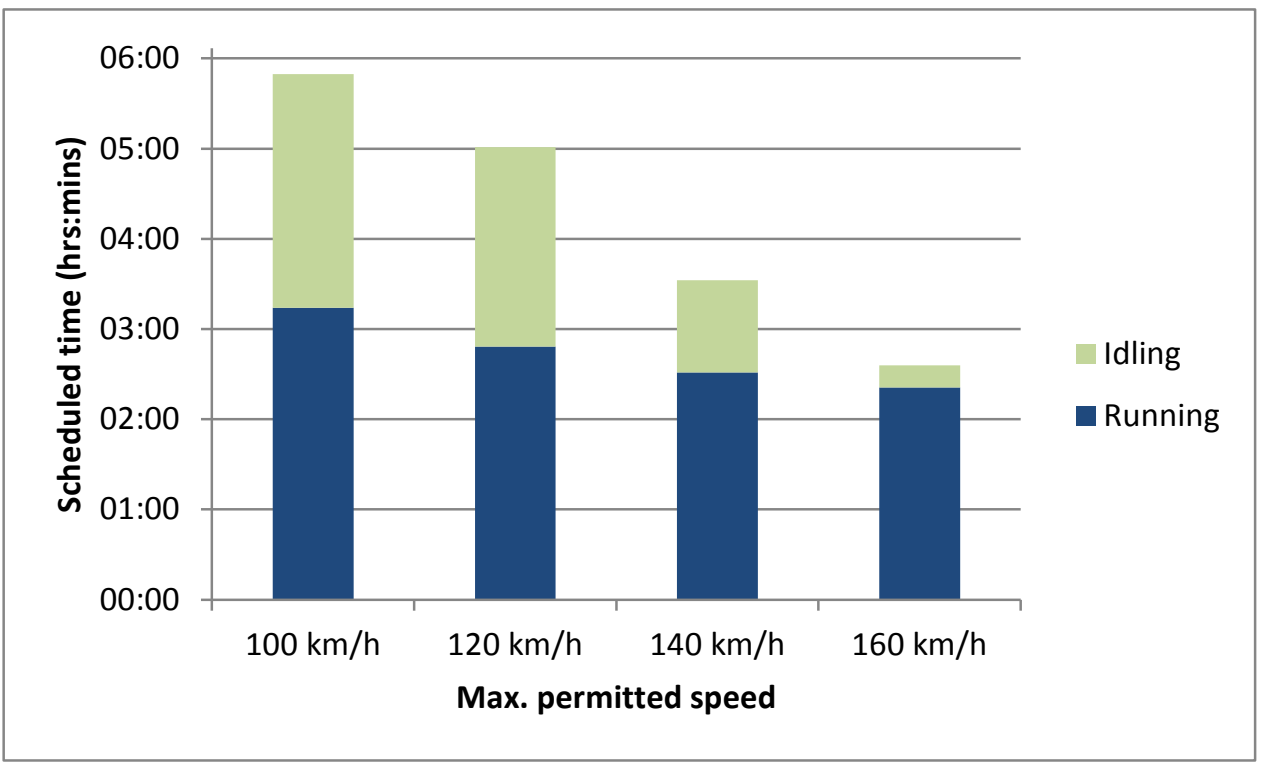

Figure 7. Scheduled time for a freight train between Mjölby and Hässleholm (400 km), daytime, when passenger services dominate. Idling time is primarily stops for overtakings.

The impact on reliability depends on how the measure affects scheduled times: if stops for overtakings can be withdrawn, the impact on delay for these trains might be negative as they lose the opportunity to catch up during scheduled but cancelled stops. Otherwise they can gain. However, it was shown that the impact on the express trains' punctuality was low. Similar results were obtained with halving of the distances between crossing loops: flexibility increases, but the effect on reliability is quite low. Table 1 summarises the findings for different measures. 
Table 1. Analysed measures to improve punctuality

\begin{tabular}{ll}
\hline Measure & Effect \\
\hline Faster freight trains & $\begin{array}{l}\text { Much shorter running times in mixed traffic but small } \\
\text { effects for express trains }\end{array}$ \\
\hline New overtaking tracks & $\begin{array}{l}\text { Slight improvement in punctuality for express trains, } \\
\text { slight deterioration for overtaken trains. Provides room for } \\
\text { more trains }\end{array}$ \\
\hline Fewer (heavier) trains & $\begin{array}{l}\text { Improvement in punctuality through fewer overtakings at } \\
\text { high capacity utilisation }\end{array}$ \\
\hline Lower stop delays for & $\begin{array}{l}\text { Improvement in punctuality for express trains } \\
\text { Can compensate for speed increase from 200 to 250 } \\
\text { express trains }\end{array}$ \\
\hline $\begin{array}{l}\text { Skip stop operation for } \\
\text { regional trains and }\end{array}$ & $\begin{array}{l}\text { Much improved punctuality and capacity for express } \\
\text { trains and freight trains, shorter travelling times for skip- } \\
\text { stop regional trains with lower frequency of service at } \\
\text { small stations }\end{array}$ \\
\hline Capacity additions for & $\begin{array}{l}\text { Much improved punctuality for express trains but longer } \\
\text { travelling times }\end{array}$ \\
\hline
\end{tabular}

\section{Discussion and conclusions}

A generally usable express train should have performance that gives short running times on tracks of different character. A future express train in long-distance traffic on conventional lines should have carbody tilting, a maximum permitted speed of at least $250 \mathrm{~km} / \mathrm{h}$, or more if the track is new and therefore has better geometry, to reach market demands.

In order to increase express train speeds on lines with mixed traffic, capacity needs to be reviewed. On single-track lines, shorter run times are an advantage for reducing the number of crossings between trains, while overtaking of freight trains will increase in the same way as on double-track lines. Regional traffic with fixed interval timetables often limits the number of train paths for other trains due to the frequent stops, which leads to low average speeds, and slightly delayed express trains become even more delayed when caught behind a regional train. This problem already exists today but will grow with larger speed differences. 
One measure that has proven to be effective for improving capacity utilisation is to introduce skip-stop traffic with commuter or regional trains to increase the average speed of slower trains and thus reduce the speed differences. Shorter distances between crossing loops (on single-track lines) and overtaking possibilities increase capacity and have a positive effect on punctuality.

Simulation of the Southern Main Line in Sweden shows that reduced dwell time delays as can be achieved with the Green Train concept compared to present express trains, may be sufficient to compensate for the poorer punctuality that might be a consequence of raising the speed.

Mixed traffic with large speed differences consumes more capacity and the system becomes sensitive to disruptions. It is possible to reduce the perturbations through different measures but the basic problem still remains. This also affects the timetabling possibilities. With higher capacity utilisation the timetable becomes less flexible, which can affect the possibilities to adapt it to the wishes of the market. In a longer perspective with increasing traffic, substantial capacity increases will be needed.

\section{References}

[1] Abril M et al. An assessment of railway capacity. Transportation Research Part E. 2008:44;774-806

[2] Andersson E: Green Train - Concept proposal for a Scandinavian high-speed train. Final report, part B. Stockholm: KTH Railway Group; 2012.

[3] Dicembre A, Ricci S. Railway traffic on high density urban corridors: Capacity, signalling and timetable. Journal of Rail Transport Planning \& Management. 2011:1;59-68

[4] Fröidh O. Perspectives for a future high-speed train in the Swedish domestic travel market. Journal of Transport Geography. 2008;16:268-277.

[5] Fröidh O: Green Train - Basis for a Scandinavian high-speed train concept, Final report, part A. Stockholm: KTH Railway Group; 2012. 
[6] Harrod, S. Capacity factors of a mixed speed railway network. Transportation Research Part E. 2009:45;830-841

[7] Lindfeldt A. Heterogeneity measures and secondary delays on a simulated double-track. In: Proceedings of Rail Copenhagen (DK); 2013.

[8] Lindfeldt O. Impacts of infrastructure, timetable and perturbations in operation of double track railway lines with mixed traffic. In: Proceedings of 12th World Conference on Transportation Research: Lisbon (PT); 2010.

[9] Lindfeldt O. Railway operation analysis [dissertation]. Stockholm: KTH; 2010

[10] Radtke A, Bendfeldt J-P. Handling of railway operation problems with RailSys. Proceedings; The 5th World Congress on Rail Research: Cologne (DE); 2001

[11] Sipilä H. Körtidsberäkningar för Gröna tåget [Running time calculations for the Green Train]. Stockholm: KTH Railway Group 0802; 2008.

[12] Sipilä H., Warg J. Kapacitetsanalys av Södra stambanan [Capacity analysis of the Southern Main Line]. Stockholm: KTH Railway Group; 2012.

[13] UIC code 406. 2nd edition, January 2012

[14] Vromans M, Dekker R., Kroon L. Reliability and heterogeneity of railway services. European Journal of Operational Research. 2006;172(2):647-665.

[15] Warg J. Effects of increased traffic volume and speed heterogeneity on the capacity of a railway with dense mixed traffic. In: Computers in Railways XIII: Computer System Design and Operation in the Railway and Other Transit Systems. Proceedings; 2012; 335-347. New Forrest (UK), 2012. 